\title{
Ensino de Estatística e de Probabilidade para os anos iniciais de escolarização: uma proposta para trabalhar resolução de problemas em contextos de jogos
}

Teaching Statistics and Probability for the initial years of schooling: a proposal to work problem solving in game contexts

\author{
Rúbia Juliana Gomes Fernandes ${ }^{1}$ \\ Guataçara dos Santos Júnior ${ }^{2}$
}

\section{Resumo}

Este artigo tem por objetivo investigar de que maneira a resolução de problemas em situações de jogos, pode ser uma ferramenta de contribuição para o ensino e a aprendizagem dos conhecimentos matemáticos referentes à Estatística e a Probabilidade. Com o intuito de atingir o objetivo apresentado, foi desenvolvida uma pesquisa numa turma de alunos do $4^{\circ}$ Ano do Ensino Fundamental de uma escola da Rede Municipal de Curitiba. Para tal, foi trabalhada uma sequência de ensino direcionado aos conteúdos básicos de matemática. A metodologia e análise utilizadas são próprias de uma pesquisa qualitativa. Ao analisar os resultados advindos do desempenho dos alunos durante a execução dessa proposta pedagógica, percebeu-se um avanço significativo quanto à aquisição dos conteúdos com relação aos conhecimentos de Matemática.

Palavras-chave: Educação Matemática. Estatística. Probabilidade. Jogos e Resolução de Problemas.

\section{Abstract}

This article aims to investigate how the resolution of problems in game situations, can be a tool to contribute to the teaching and learning of mathematical principles and knowledge related to Statistics and Probability. In order to achieve the goal presented was developed in a research group of students of the 4th year of elementary school in a school Municipal de Curitiba. To this end, has crafted a teaching sequence directed to basic math content. The methodology used in this research is applied, descriptive, and the results were analyzed in qualitative terms. By analyzing the proceeds of student performance during

\footnotetext{
${ }^{1}$ Doutoranda no programa de Ciência e Tecnologia da Universidade Tecnológica Federal do Paraná UTFPR / Câmpus - Ponta Grossa - rufernandes@hotmail.com. Atua como professora de matemática e pedagoga da rede pública de ensino em Curitiba.

${ }^{2}$ Doutor em Ciências Geodésicas pela Universidade Federal do Paraná. Atua como professor no programa de Pós-Graduação em Ensino de Ciência e Tecnologia da Universidade Tecnológica Federal do Paraná UTFPR / Câmpus - Ponta Grossa. guata39@gmail.com.br.
} 
the execution of this pedagogical proposal, it was noticed a significant advance on the acquisition of content in relation to knowledge of mathematics.

Keywords: Mathematics Education. Statistics. Probability. Games and Problem Solving.

\section{Introdução}

A aprendizagem da matemática pode ser compreendida como a interrelação de conceitos científicos e saberes não formalizados utilizados na vida cotidiana dos indivíduos. Cabe à escola aproximar e articular essas duas questões, buscando romper o paradigma que tem se perpetuado no entendimento dos alunos, que a matemática da escola é uma e da vida real outra. Além disso, a instituição escola deverá considerar em que circunstâncias poderão valer-se dos conhecimentos matemáticos acadêmicos na efetivação de situações reais que necessitem de solução.

Desta forma, percebe-se que o ensino da matemática pode-se configurar como elemento crucial dentro do contexto escolar, visto que sua importância extrapola a mera reprodução sistemática curricular intraescolar e vai além da sala de aula, gerando reflexões sobre situações cotidianas a partir de conhecimentos matemáticos e possibilitando ao estudante estabelecer paralelos entre o que foi aprendido e suas necessidades sociais. Nesta vertente de pensamento, Lopes (2008, p. 62) afirma que:

[...] não faz sentido trabalharmos envolvendo conceitos matemáticos que não estejam vinculados a uma problemática. Propor coleta de dados desvinculada de uma situação-problema não levará à possibilidade de uma análise real. Construir gráficos e tabelas desvinculados de um contexto ou relacionados a situações muito distantes do aluno pode estimular a elaboração de um pensamento, mas não garante o desenvolvimento de sua criticidade.

A educação estatística tem como finalidade proporcionar e favorecer a elaboração e apropriação do pensamento estatístico, haja vista que estes conhecimentos são indispensáveis aos estudantes e indivíduos de modo geral. 
Desse modo, pode-se dizer que a prática de ensino da estatística na escola deverá permitir tais análises, bem como oportunizar ao aluno momentos de ação e reflexão sobre demandas sociais onde este conteúdo se configura.

Percebe-se a necessidade de uma atuação pedagógica distinta durante as aulas de matemática, por que os alunos em sua grande maioria exploram e operam com os conceitos e conhecimentos matemáticos de forma mecânica, sem compreensão dos elementos e estruturas cognitivas que as permeiam, em situações problemas reais.

A resolução de problemas no contexto de jogos pode contribuir para o desenvolvimento da Matemática. Cabe ressaltar que resolver problemas, em situações de jogos ou não, modifica as percepções matemáticas dos sujeitos e estes "poderão gerar o gosto pelo trabalho mental e deixar, por toda a vida, a sua marca na mente e no caráter" (POLYA, 1978, p.87).

A sistematização pedagógica com a resolução de problemas em contexto de jogos, se bem estruturada e encaminhada, pode possibilitar o desenvolvimento de inúmeras habilidades, pois ao jogar, os alunos têm a oportunidade de "resolver problemas, investigar e descobrir a melhor jogada; refletir e analisar as regras, estabelecendo relações entre os elementos do jogo e os conceitos matemáticos". Podemos dizer que um [...] "jogo possibilita uma situação de prazer e aprendizagem significativa nas aulas de matemática" (SMOLE, 2007, p.09).

Portanto, o presente estudo tem como objetivo investigar de que maneira a resolução de problemas durante a realização de jogos, poderá contribuir para o ensino e a aprendizagem dos conhecimentos matemáticos referentes à Estatística e a Probabilidade.

\section{2 ensino e a aprendizagem da Matemática}

Percebe-se que a matemática faz parte das invenções da humanidade, ao considerar que a criação é inerente aos seres humanos, os quais buscam "explicar, entender, manejar e conviver com a realidade sensível, perceptível, e 
com seu imaginário, naturalmente dentro de um contexto natural e cultura" (D’AMBRÓSIO, 1996, p.7), na tentativa de compreender seu entorno e solucionar problemas, buscando conectar-se com situações vivenciadas e já resolvidas e representando modelos matemáticos.

Acredita-se que o processo de ensino e aprendizagem de conceitos matemáticos seja uma ação interativa entre os conhecimentos sistematizados cientificamente, e a matemática como atividade social humana. Nesse sentido, os Parâmetros Curriculares Nacionais (PCNs), os quais são direcionadores curriculares nacionais, uma fonte de pesquisa para nortear o trabalho docente, de modo que este se postule como um diferenciador no processo pedagógico, ao favorecer e incitar a apropriação e desenvolvimento cognitivo dos conhecimentos matemáticos dos estudantes. A partir da década de 1990, os Parâmetros Curriculares Nacionais (PCNs) passaram a existir depois da nova lei de Diretrizes e Bases da Educação Nacional - LDB (Lei 9394/96, de 20 de dezembro de 1996) objetivando assegurar o currículo para a educação básica dispostos em dois segmentos: Ensino Fundamental e Ensino Médio.

Cabe destacar que os PCNs dedicaram um olhar especial com relação à necessidade da educação escolar aproximar-se da formação cidadã. Nesse viés, compreende-se que a matemática pode ser um instrumento de captação e leitura de mundo, além de "o reconhecimento dessa área do conhecimento como estimuladora do interesse, curiosidade, espírito de investigação e o desenvolvimento da capacidade de resolver problemas", e nesse contexto em especial aos problemas matemáticos, com vistas aos princípios estatísticos.

Os Parâmetros Curriculares Nacionais indicam que:

[...] tanto nos objetivos educacionais que propõem quanto na conceitualização do significado das áreas de ensino e dos temas da vida social contemporânea que devem permeá-las, adotam como eixo o desenvolvimento e capacidades do aluno, processo em que os conteúdos curriculares atuam não como fins em si mesmos, mas como meios para a aquisição e desenvolvimento dessas capacidades (BRASIL, 1997, p. 33).

Nessa perspectiva curricular, os conteúdos estão distribuídos em blocos: números e operações, espaço e forma, grandezas e medidas, e tratamento da 
informação. Com relação ao último bloco tratamento da informação podem-se elencar os seguintes conteúdos: estatística, combinatória e probabilidade.

Com relação à estatística, "a finalidade é fazer com que o aluno venha a construir procedimentos para coletar, organizar, comunicar e interpretar dados, utilizando tabelas, gráficos e representações que aparecem frequentemente em seu dia-a-dia" (BRASIL, 1997, p.56). Percebe-se que na vida em sociedade há grande importância dos conhecimentos estatísticos, por isso cabe às instituições escolares focalizarem e sistematizarem as suas práticas pedagógicas com vistas a essa realidade oportunizando processos de ensino e aprendizado reais. Desta forma, entende-se que o trabalho relativo a noções de estatística não deverá estar pautado apenas "na definição de termos ou de fórmulas envolvendo tais assuntos" (BRASIL, 1997, p.57).

Ainda com vistas ao trabalho pedagógico nos dois primeiros ciclos, os PCNs (1997) sugerem atividades de interesse e conhecimento dos estudantes, como por exemplo, datas de aniversários, objetivando a elaboração de lista pertinente ao tema segundo um critério previamente estabelecido. Após esse movimento, os estudantes podem analisar, discutir e avaliar, para em seguida, efetivar a construção de um gráfico de barras (explica-se que essa é outra forma de expressar os aniversariantes). Além disso, cabe destacar "dados referentes aos alunos, como por exemplo: peso, altura, nacionalidade das avós, times de futebol de sua preferência, podem ser trabalhados e apresentados graficamente" (BRASIL, 1997, p.133).

Carvalho (2000), em suas pesquisas sobre as propostas curriculares das instituições brasileiras, observou aspectos positivos e negativos relacionados aos pontos supracitados. Reportando-se exclusivamente aos enfoques positivos relacionados pelo autor, ao Ensino Fundamental e em especial aos anos iniciais, ressalta-se que:

[...] o tratamento e análise de dados por meio de gráficos; a introdução de noções de estatística e probabilidade; a percepção de que a matemática é uma linguagem; o reconhecimento da importância do raciocínio combinatório; um esforço para embasar a proposta em estudos recentes de educação matemática; a percepção de que a função da Matemática escolar é preparar o 
cidadão para uma atuação na sociedade em que vive (CARVALHO, 2000, p.122-123).

No que diz respeito, ao pensamento probabilístico torna-se fundamental oportunizar aos alunos o embate com situações reais diversificadas como, por exemplo: jogo de regras, resolução de situações problemas que pode favorecer a elaboração de estratégias, a probabilidade:

É apresentada com a finalidade de promover a compreensão de grande parte dos acontecimentos do cotidiano que são de natureza aleatória, possibilitando a identificação de resultados possíveis desses acontecimentos. Destacam-se o acaso e a incerteza que se manifestam intuitivamente, portanto cabendo à escola propor situações em que as crianças possam realizar experimentos e fazer observações dos eventos (LOPES, 2003, p.123).

Nesse aspecto a estatística e a probabilidade podem ser apresentadas utilizando o recurso da matematização que significa organizar, formular, sistematizar, criticar e desenvolver mecanismos próprios para compreender (SKOVSMOSE, 1990). Para que esse processo se efetive é indispensável que docentes e discentes encontrem-se no domínio da situação de aprendizagem.

Tais questões podem ser sistematizadas no contexto escolar, por meio de recursos didáticos, como os jogos e a resolução de problemas, na tentativa de ofertar aos estudantes uma maneira interativa e dinâmica de explorar os conteúdos matemáticos, enfocando os conceitos estatísticos e probabilísticos, priorizando as relações matemáticas contextualizadas socialmente em detrimento da matemática escolar repetitiva, e por vezes desconectas da vida cotidiana dos alunos.

Nesse sentido, verifica-se que a função do ensino da matemática vai além das grades curriculares restritas ao conteúdo pleno, pois deve favorecer reflexões que extrapolam as paredes escolares. Já sobre os pontos elencados por Carvalho (2000) como negativos com relação ao ensino da matemática escolar pode-se citar as ênfases excessivas aos conteúdos e técnicas algorítmicas operatórias, em detrimentos dos conceitos, bem como poucas referências que possam subsidiar o processo educativo para o desenvolvimento de pensamento matemático no campo do cálculo mental, estimativa e aproximações. 
Entende-se, assim, que para o sujeito estar, de fato, educado matematicamente, as metodologias desenvolvidas pelo professor devem ser exploradas de modo que [...] priorizem a "criação de estratégias, a comprovação, a justificativa, a argumentação, o espírito crítico, e favoreçam a criatividade, o trabalho coletivo, a iniciativa pessoal e a autonomia advinda do desenvolvimento da confiança na própria capacidade" de conhecer e enfrentar desafios (BRASIL, 1997, p. 26).

Pais (2001) considera que a pretensão central do ensino da matemática, deve ser a formação integral do aluno de forma autônoma. Este deve ser capaz de perceber e utilizar os conhecimentos matemáticos escolares em situações reais, visualizando a utilidade e aplicabilidade desses conhecimentos e conceitos matemáticos sistematizados na esfera educacional. Nessa conjectura, acredita-se que os alunos são capazes de contribuir na construção do saber ao qual estão tendo contato, e a escola deixa de ser algo fora da sua realidade começando a fazer parte do seu cotidiano de maneira significativa.

Reiterando as colocações de Pais (2001) e dos PCN (1997), reflete-se que, ao apoiar as intervenções pedagógicas numa perspectiva metodológica de ensino que aproxime e considere os alunos, o professor deverá proporcionar maior interesse, por parte do aluno, pela escola. Para tanto:

[...] é preciso que as crianças sintam-se participantes num ambiente que tenha sentido para elas, para que possam se engajar em sua própria aprendizagem. O ambiente da sala de aula pode ser visto como uma oficina de trabalho de professores e alunos, podendo transformar-se num espaço estimulante, acolhedor, de trabalho sério, que favoreça o desenvolvimento dos alunos, bem como de fornecer propostas desafiadoras a serem superadas. [...] Nesse sentido, os grupos de trabalho tornam-se indispensáveis, assim como diferentes estratégias e recursos didáticos (SMOLE; DINIZ; CÂNDIDO, 2000, p.11).

Compreende-se como essencial lançar mão de estratégias metodológicas distintas alguma bastante aplicada já na esfera educacional, como: quadro negro e giz, e outras nem tanto como: jogos, resolução de problemas, ambientes interativos computacionais entre outras ferramentas pedagógicas. Portanto, 
acredita-se que esse cenário escolar, pode propiciar a interação dos estudantes com o objeto do conhecimento, ou seja, os princípios matemáticos.

\section{A resolução de problemas e os jogos}

A principal finalidade desta proposta pedagógica é ensinar matemática, por meio dos jogos e resolução de problemas. Os PCNs nomeiam a resolução de problemas como cenário principal para o ensino da matemática, e por consequência da Probabilidade, já que o pensar e o fazer são mobilizados, com isso, desenvolvendo-se quando o aluno está engajado de fato no enfrentamento de um desafio. O envolvimento em situações complexas e diversificadas promove aos alunos a possibilidade de pensar com autonomia, construir estratégias de resolução e argumentação, relacionados a diversos conhecimentos e, por fim, perseverando na busca de soluções, e, para tanto, os desafios devem ser reais (BRASIL, 1997).

Nesse sentido, a resolução de problemas é uma ferramenta eficaz para o processo de ensino e aprendizagem. Acredita-se que os conceitos e os procedimentos da disciplina de matemática, em sua maioria, senão todos podem ser mais sistematizados por meio da resolução de problemas, "os estudantes devem resolver problemas não para aplicar matemática, mas para aprender nova matemática. Quando os alunos se ocupam de tarefas bem escolhidas baseadas na resolução de problemas e se concentram nos métodos de resolver", desse modo, o resultado são novas compreensões da matemática (VAN DE WALLE, 2009, p.57).

Na concepção de Macedo, Petty e Passos (2005), em qualquer jogo, temse uma situação-problema, ou seja, um objetivo que se pretende alcançar ou algo a ser solucionado pelo sujeito ou por um grupo de sujeitos. Assim, o resultado do jogo (este, rigorosamente deverá obedecer aos procedimentos pré-estabelecidos) nada mais é do que um sistema de regras que tem por finalidade delimitar a ação dos envolvidos. 
O jogo, como qualquer ação, envolve regulação. Regular de um modo às ações [...]. O aspecto mais significativo dessa regulação é o jogar com regras. Daí, podemos afirmar que, como ponto de chegada, o jogo acontece de fato quando os participantes executam ações subordinadas às regras e comprometidas com o objetivo final da partida. Para nós, jogar favorece a aquisição de conhecimento, pois o sujeito aprende sobre si próprio (como age e como pensa), sobre o próprio jogo (o que caracteriza como vencer), sobre as relações sociais relativas ao jogar (tais como competir e cooperar) e também sobre conteúdos escolares (semelhantes a certos temas trabalhados no contexto escolar), (MACEDO, PETTY e PASSOS (2005, p. 28).

Entende-se que a resolução de problemas e o jogo, quando utilizados como objetos pedagógicos objetivando o desenvolvimento cognitivo, possuem algumas semelhanças que os aproximam enquanto estratégias pedagógicas. Aqui, nos reportarmos a duas delas. "A semelhança seria encontrada no sujeito que executa a ação. Só existirá jogo se o sujeito tiver vontade de jogar e, da mesma foram, só existe problema se o indivíduo se sentir desestruturado, [...] o problema só é problema se ele é do indivíduo". No que trata da segunda, encontra-se nas fases do desenvolvimento. "No problema distinguem-se as fases: problema desencadeador, construção do conceito; e a aplicação do conceito. E, no jogo, as fases: jogo desencadeador; reinvenção do jogo; e descoberta de estruturas", (MOURA, 1992, p.21).

É importante destacar que a concepção de jogo utilizada nessa pesquisa considera que

O jogo será conteúdo assumido com a finalidade de desenvolvimento de habilidades de resolução de problemas, possibilitando ao aluno a oportunidade de estabelecer planos de ação para atingir determinados objetivos, a executar jogadas segundo este plano e a avaliar a eficácia destas jogadas nos resultados. Desta maneira, o jogo aproxima-se da Matemática via desenvolvimento de habilidade de resolução de problemas (MOURA, 1992, p.21).

Para a autora, é possível aproximar os pressupostos filosóficos da resolução de problemas e dos jogos. Ao observar que na resolução de problemas, as etapas, originalmente apresentadas por Polya (1978), eram as seguintes: compreensão do problema, estabelecimento de um plano, execução do plano e 
retrospecto. Com relação ao jogo, as etapas são: compreensão do jogo, estabelecimento de estratégias, execução das jogadas e avaliação do jogo.

No contexto escolar, a atividade de jogar desempenha papel importante no desenvolvimento de habilidades de raciocínio lógico, dedutivo e indutivo. Além, da linguagem, criatividade, atenção e busca por soluções, elementos fundamentais para o processo de ensino e aprendizagem da Matemática, e nesse caso, da Probabilidade. Durante os momentos de jogo, o aluno deixa de ser elemento receptor passivo de informações e/ou conhecimentos, e torna-se agente ativo, vivenciando o processo de construção e/ou sistematização do seu próprio conhecimento. Para que isso, de fato aconteça, é fundamental que o professor compreenda que "a justificativa da utilização de jogos em sala de aula não pode restringir-se ao caráter motivacional, mas que depende da ação intencional, planejada, executada, registrada, avaliada e compartilhada pelos alunos e professores" (GRANDO, 2007, p.49).

Nesse sentido, o jogo pode ser sistematizado como ação pedagógica associada à resolução de problemas,

a união entre o jogo e a resolução de problemas está intimamente vinculada à intencionalidade do professor, que é um dos arquitetos do projeto pedagógico do trabalho coletivo da escola. Este projeto tem começo - a cultura primeira e um fim - a cultura elaborada, sendo ambos móveis; trata-se do conhecimento em movimento. Aquele conhecimento que é síntese de um processo passa a ser começo de outros, num movimento crescente. [...] combinar jogo e resolução de problemas é muito mais que uma simples atitude, é uma postura que deve ser assumida na condução do ensino. [...] fazer isto é dar um sentido humano ao jogo, à resolução de problemas e, sendo assim, à Educação Matemática (MOURA, 1992, p.51-52).

Portanto, acredita-se que as atividades pedagógicas estruturadas utilizando a resolução de problemas por meio de jogos, podem configurar-se como recurso valioso, na tentativa de viabilizar as relações sociais e educacionais que estes, favorecem e oportunizam instigando nos alunos atitudes perspicazes, criativas, bem como a observação de situações reais e a criticidade para se posicionar. 


\section{Procedimentos metodológicos}

A partir das inquietações em relação à maneira como os discentes se comportam e como estruturam a organização de pensamento lógico estatístico e probabilístico nos processos pedagógicos de ensino e aprendizagem durante a resolução de situações problemas por meio de jogos, buscou-se refletir de que forma a postura didática do professor favorece a aquisição desses conhecimentos matemáticos.

A metodologia e análise utilizadas são próprias de uma pesquisa qualitativa. O espaço amostral foi composto por 32 alunos do $4^{\circ}$ ano da Rede Municipal de Ensino de Curitiba.

1ㄹ Etapa: solicitar que os alunos tragam jogos diversos, para que haja a escolha de um como sendo jogo preferido da turma, por meio de um instrumento avaliativo.

$2^{\text {a }}$ Etapa: Prosseguindo os alunos tinham como tarefa responder ao instrumento avaliativo sobre sua preferência em relação aos jogos, para elencar somente um.

3aㅡ Etapa: Na sequência fez-se a tabulação dos dados coletivamente, para descobrir qual seria o jogo de maior preferência.

4a Etapa: A tarefa seguinte proposta, amparou-se nos recursos tecnológicos para apresentação dos dados coletados, a partir do instrumento avaliativo, por meio da tabulação e representação gráfica.

\section{Apresentação e discussão dos resultados}

A pesquisa foi desenvolvida durante seis aulas de matemática, na qual se buscou observar e refletir sobre a ação dos sujeitos participantes na resolução de problemas em circunstâncias de jogos no ambiente escolar. O início desse estudo interventivo ocorreu em momentos de observação e análise do comportamento 
dos discentes durante a resolução de situações problemas e da dificuldade apresentada pelos mesmos, apoiando-se em geral nos procedimentos e técnicas mecânicas operatórias, sem muita clareza sobre o porquê dessa utilização.

$\mathrm{Na}$ tentativa de minimizar essa questão, optou-se pela utilização de jogos pensando em sistematizar os conteúdos matemáticos advindo de uma prática real, os alunos atuavam ativamente. Vislumbrou-se, que a partir da ludicidade poderia se sistematizar práticas pedagógicas que venham ao encontro das necessidades pedagógicas dos alunos, para isto partiu-se da premissa de que os jogos podem ser grandes aliados no ensino da matemática.

A dinâmica iniciou-se com a proposta feita aos alunos para que trouxessem para a escola jogos que tivessem em casa. Este encontro teve por finalidade instigar e promover o desenvolvimento do raciocínio lógico dedutivo, perspicácia e criatividade. Os alunos nessa ocasião tiveram a possibilidade de escolher quais as atividades queriam participar respeitando as regras desta.

Nessa tarefa a professora atuou como uma colaboradora no que os estudantes necessitavam, porém não interviu nas escolhas e nem sistematizou conhecimentos acadêmicos; foi o momento de exploração e interação da turma com os jogos. Para complementar os jogos que os alunos trouxeram, a professora deixou a disposição mais alguns como: Jogo de xadrez, trilha, dama, resta um, pebolim, botão, uno, mico, detetive, dominó, batalha naval, pega varetas, monopólio, banco imobiliário, stop.

Os alunos primeiramente ficavam pouco tempo em cada um dos jogos, na ânsia de vivenciar todas as possibilidades do momento. Após esse momento inicial, concentraram-se em seus jogos preferidos, e realizaram acordos para utilização de alguns, os quais a procura era maior.

Cabe lembrar que para as crianças os jogos "são fonte de significados e, portanto, possibilitam compreensão, geram satisfação, formam hábitos que se estruturam num sistema" (BRASIL, 1997, p. 35). Ter a prática do jogo nas aulas de matemática é deveras importante, visto que favorecem novos aprendizados por meio da reflexão e ação além de favorecer "uma mudança significativa nos 
processos de ensino e aprendizagem que permite alterar o modelo tradicional de ensino"(SMOLE, 2007, p. 9).

Após esse momento de livre escolha, realizou-se uma roda de conversa para discussões e análises dos aspectos por eles considerados positivos e negativos durante a execução das atividades propostas. Além disso, a realização de uma avaliação individual e autodirigida, na qual os participantes tiveram poder decisório sobre suas preferências de jogo, podendo avaliar jogo a jogo, segundo três critérios pré-estabelecidos (Gostou, Mais ou menos, não gostou).

Sequencialmente, após a conversa e explicação do instrumento avaliativo a turma o preencheu. Em seguida, os alunos expuseram quais os motivos que os levaram a avaliar que gostaram de um jogo, e não de outro. A professora foi instigando a turma para que argumentasse coerentemente, não sendo aceito o simplesmente, não gostei.

Dentre as questões que surgiram neste momento pode-se destacar: Que fatores foram importantes para chegar a essa conclusão? Não gostou das regras? Não entendeu o jogo? Não teve êxito nas jogadas? Não jogou o tempo suficiente nenhum dos jogos para gostar de algum? Todos esses pontos foram levantados em roda de conversa para que os alunos conjecturassem uma opinião formada sobre os itens que iriam avaliar.

Essas questões foram debatidas e respondidas coletivamente. Surgiram colocações interessantes como a da Aluna "A": "Gostei bastante dessas aulas, pois assim fica mais fácil aprender matemática. " Aluno "G": "É, legal saber que quando estamos jogando, também estamos aprendendo". Aluno "R": "Nossa, nem sabia que ficar pensando nas jogadas, era raciocínio lógico, como a professora falou". Aluna "M": "Eu gostei dessas aulas, acha que na aula de matemática, a gente ia ficar só fazendo continhas e resolvendo problemas". Aluno "C": "No começo não gostei do jogo Uno, pois não conhecia esse jogo e achei difícil entender, só perdi, depois que entendi, achei bem legal, até já consegui pensar num jeito de tentar ganhar". Após esse momento de argumentações, os alunos responderam o instrumento investigativo. 
Pode-se dizer que está foi uma dinâmica de favorecimento à criticidade, visto que se pautou na criatividade e curiosidade dos estudantes. De acordo com Freire (1992, p. 18):

A curiosidade como inquietação indagadora, como inclinação ao desvelamento de algo, como pergunta verbalizada ou não, como procura de esclarecimento, como sinal de atenção que sugere e alerta faz parte integrante do fenômeno vital. Não haveria criatividade sem a curiosidade que nos move e que nos põe pacientemente impacientes diante do mundo que não fizemos, acrescentando a ele algo que fazemos.

Em seguida, elencou-se um jogo de preferência pela turma para sistematização em sala de aula dos conceitos matemáticos que estavam presentes nos momentos interativos da tarefa, ou seja, as situações problemas a serem resolvidas no jogo. Em linhas gerais os alunos tiveram grande aceitação por todos os jogos propostos pela professora e por seus colegas. O jogo Uno foi escolhido pela turma, como o mais bem aceito, para que sequencialmente haja um encaminhamento pedagógico por parte do professor. Conforme, pode-se observar no gráfico, a seguir, na figura 1.

Figura 1 - Gráfico expressando aceitação e rejeição dos alunos.

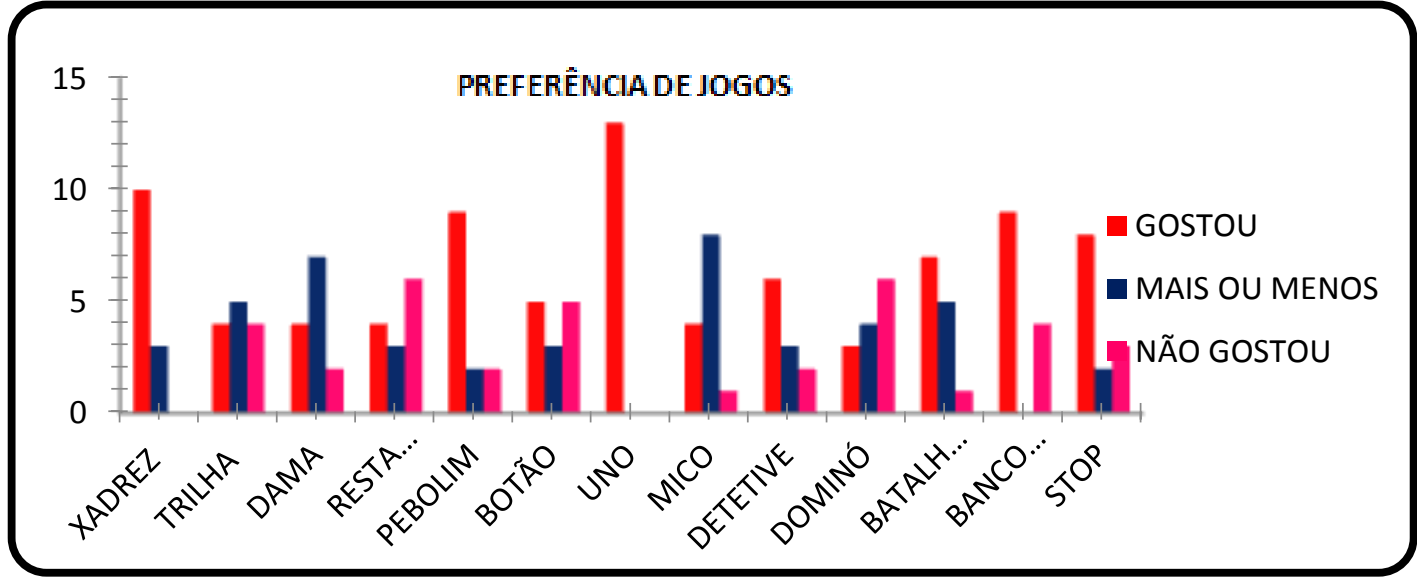

Fonte: Autores.

Para que a turma pudesse tecer essa conclusão, com relação ao nível de aceitação de cada um dos jogos propostos, a professora organizou coletivamente um momento de coleta, organização, tabulação e expressão gráfica das 
informações advindas do instrumento avaliativo. Assim, tiveram condições de perceber claramente suas escolhas dentro do contexto da turma, necessitam reportar-se a conceitos matemáticos estatísticos. Isso indica que, apresentar situações-problemas que envolvam, desafiem e motivem o aluno a resolvê-las, favorece ao mesmo pensar produtivamente (DANTE, 2005, p.11).

Ratificam-se as práticas pedagógicas aplicadas, ao ponderar a seguinte afirmação:

[...] não faz sentido trabalharmos atividades envolvendo conceitos estatísticos e probabilísticos que não estejam vinculados a uma problemática. Propor coleta de dados desvinculada de uma situação-problema não levará à possibilidade de uma análise real. Construir gráficos e tabelas desvinculados de um contexto ou relacionados a situações muito distantes do aluno pode estimular a elaboração de um pensamento, mas não garante 0 desenvolvimento de sua criticidade (LOPES, 2008, p. 62).

Mediante as considerações tecidas pelos envolvidos nesse processo interativo tanto do professor quanto do aluno, para o instante seguinte, realizou-se uma conversa dirigida com os alunos aonde a intenção era diagnosticar em que momentos eles puderam perceber a utilização dos princípios matemáticos durante a realização dos jogos, ou se não aplicaram tais preceitos em nenhum momento. Inicialmente a turma teve dificuldade em mencionar quaisquer relações matemáticas que utilizaram.

Nessa ocasião, vários alunos consideravam que não haviam utilizado a matemática para nada, pois não realizaram nenhuma continha, e nem resolveram nenhum problema. O aluno "F" logo disparou: "eu usei matemática" - quando estava jogando banco imobiliário, "pois precisava cobrar os aluguéis das minhas propriedades, comprar outras propriedades e daí fazia as contas para ver se estava certo o que me pagavam. " A professora, aproveitando essa colocação ponderou com os alunos que em todos os jogos, foram aplicados conceitos matemáticos, e que estes não precisam ser necessariamente contas ou cálculos.

Ao resolver as situações problemas pertinentes aos próprios jogos, como optar por uma jogada e não por outra, observar uma ocorrência do jogo, e criar outra estratégia para resolvê-la, os alunos analisaram as jogadas dos adversários, 
para traçar sua linha de raciocínio e ação, enquanto jogador e desenvolveram seu raciocínio matemático. Para validar suas estratégias, os estudantes refletiram sobre as mesmas, a partir da obtenção do sucesso ou não, aplicando conceitos aditivos, subtrativos, multiplicativos e divisórios se assim fosse necessário para interação de alguns dos jogos como, por exemplo: o banco imobiliário e monopólio.

Essa ação não significou que houvesse obrigatoriedade de utilização desses procedimentos matemáticos, podendo utilizar o raciocínio lógico dedutivo, a resolução de problemas advindos dos jogos, a elaboração de estratégias para alcançar os objetivos delimitados, a constatação se conseguem validar as hipóteses traçadas, e se acaso isso não ocorresse, um novo percurso precisaria ser delineado. Desse modo, os PCNS corroboram com as questões discutidas nesse estudo, ao afirmar que os saberes matemáticos são ferramentas entendidas como essenciais nas seguintes perspectivas [...] na "formação de capacidades intelectuais, na estruturação do pensamento, na agilização do raciocínio dedutivo do aluno, na sua aplicação a problemas, situações da vida cotidiana e atividades do mundo do trabalho e no apoio à construção de conhecimentos" em outras áreas curriculares (BRASIL, 1997, p.25).

Assim, os alunos foram conduzidos para começar entender que a matemática, não se limita exclusivamente a aplicabilidade de princípios procedimentos e operatórios, e que por muitas vezes não tem conexão alguma com suas vivências reais. A partir dessa concepção criada pelos participantes pode-se dizer que as experiências ali vivenciadas "poderão gerar o gosto pelo trabalho mental e deixar, por toda a vida, a sua marca na mente e no caráter" (POLYA, 1978, p.87).

Percebe-se que não basta desenvolver um processo de ensino fora de um contexto problematizado real que oportunize reflexões sobre conceitos probabilísticos e estatísticos. É fundamental que o estudante pense sobre 0 problema e tenha subsídios para solucioná-lo a partir de seu contexto. Isso, também, não significa somente sistematizar pedagogicamente os conceitos do 
senso comum que o aluno traz de seu convívio social. Deve-se aproveitá-los, para torná-los científicos, vislumbrando contribuir para que os indivíduos comecem gradativamente a posicionar-se reflexivamente nas atividades de ensino, haja vista ser situações com as quais já possuem o mínimo de familiaridade e conhecimento.

Portanto, compreende-se que o ensino da matemática, não pode ser tratado de forma isolada e distante da realidade social dos alunos. E, sim conectada as experiências e saberes empíricos com os conhecimentos científicos.

\section{Considerações finais}

O presente estudo teve como objetivo investigar de que maneira a resolução de problemas em situações de jogos, pode ser uma ferramenta de contribuição para o ensino e a aprendizagem dos conhecimentos matemáticos referentes à Estatística e a Probabilidade.

Considera-se que o impacto das novas descobertas tecnológicas é atual e, por sua vez, acarreta inúmeras mudanças sociais e na educação, produzindo transformações na natureza do saber. Esta geração pode ser vista como tecnológica, nestas atividades sistematizadas o aprender a interagir, a operacionalizar e executar as proposições dos jogos de regras podem favorecer as práticas educativas, pois ao jogarem precisam elaborar e criar mecanismos eficientes para resolver cada problema existente nas fases do processo.

Assim, o professor também precisa estar ciente dos novos espaços de aprendizagem que estão surgindo, principalmente no mundo em que seu aluno está inserido. As novas formas de acesso ao conhecimento tecnológico que começam a se consolidar nas instituições escolares: os jogos, recursos tecnológicos, ferramentas interativas entre outros, vêm despertando grande interesse dos alunos, e indicando que podem ser compreendidas com recursos pedagógicos valiosos nos processos de ensino e aprendizagem. 
Neste processo educativo, a postura do professor durante as aulas teve papel fundamental, ao oportunizar uma prática pedagógica ativa, assim professor e alunos tiveram a oportunidade de adotar postura ativa e participativa, como agentes transformadores frente ao processo de ensino e aprendizagem dos saberes e conceitos matemáticos.

Portanto, destaca-se que o objetivo de investigar de que maneira a resolução de problemas em situações de jogos, pode ser uma ferramenta de contribuição para o ensino e a aprendizagem de princípios e conhecimentos matemáticos referentes à Estatística e Probabilidade.

\section{Referências}

BRASIL. Secretaria de Educação Fundamental. Parâmetros curriculares nacionais. Brasília: MEC/SEF, 1997.

CARVALHO, J. B. P. As propostas curriculares de matemática. São Paulo: Fundação Carlos Chagas, 2000.

DANTE, Luiz Roberto. Didática da Resolução de Problemas de Matemática. São Paulo: Ática, 2005.

FREIRE, Paulo. Pedagogia da esperança: um reencontro com a pedagogia do oprimido. Rio de Janeiro: Paz e Terra, 1992.

GRANDO, R. C. O jogo e a matemática no contexto da sala de aula. São Paulo: Paulus, 2004.

LOPES, C. A. E. O ensino da estatística e da probabilidade na educação básica e a formação dos professores. Revista: Caderno. Cedes, Campinas, vol. 28, n. 74, p. 5773, jan./abr, 2008. Disponível em: http://www.cedes.unicamp.br . Acesso em: 07/08/2012.

O conhecimento profissional dos professores e suas relações com Estatística e Probabilidade na Educação Infantil. 2003. 281f. Tese (Doutorado em Educação) - Universidade Estadual de Campinas, Campinas, 2003.

MOURA, M. O. A construção do signo numérico em situação de ensino. Tese de Doutorado. São Paulo, SP, Faculdade de Educação, USP, 1992.

KISHIMOTO, T. M. Jogo, brinquedo, brincadeira e a educação. (Org). $2^{\mathrm{a}}$ ed. São Paulo: Cortez, 1997. 
MACEDO, L.; PETTY, A. L. S.; PASSOS, N. C. Os Jogos e o lúdico na aprendizagem escolar. Porto Alegre: Artmed, 2005.

PAIS, L. C. Didática da matemática: uma análise da influência francesa. Belo Horizonte: Autêntica, 2001.

POLYA, G. A arte de resolver problemas: um enfoque do método matemático. Rio de Janeiro: Interciência, 1949. Tradução e adaptação: Heitor Lisboa de Araújo.

RAU, M. C. T. D. O lúdico na prática pedagógica de educação infantil e anos iniciais no ensino fundamental: Concepções e práticas, 2006.

SKOVSMOSE, O. Reflective knowledge: its relation to the mathematical modellig process. Int. J. Math. Educ. Sci. Technol., London, v. 21, n. 5, p. 765-779, 1990.

SMOLE, K. S.; DINIZ, M. I.; CÂNDIDO, P. Brincadeiras matemáticas na educação infantil. Porto Alegre: Artmed, 2000.

SMOLE, K. S.; DINIZ, M. I. Cadernos do Mathema: Jogos de matemática de 6․ a 9․ ano. Porto Alegre: Artmed, 2007.

VAN DE WALLE, J. A. Matemática no ensino fundamental: formação de professores e aplicação em sala de aula. Tradução de Paulo Henrique Colonese. 6. ed. Porto Alegre: Artmed, 2009. 